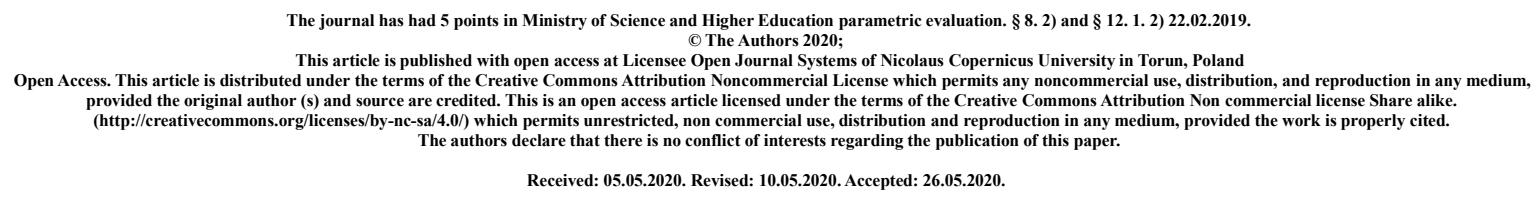

\title{
Age of peak performance of elite men in middle- and long-distance running in the Czech Republic between 1945-2019
}

\author{
Petr Bahenský, Tomáš Tlustý
}

Name

Petr Bahenský

ORCID iD

https://orcid.org/0000-0002-5928-2749

Affiliation

University of South Bohemia in České Budějovice, Faculty of Education

Country

Czech Republic

Bio Statement Department of Sports Studies

Principal contact for editorial correspondence.

Name

Tomáš Tlustý

ORCID iD

https://orcid.org/0000-0001-6571-9161

Affiliation University of South Bohemia in České Budějovice, Faculty of Education

Country Czech Republic

Bio Statement Department of Sports Studies

\begin{abstract}
Background: A peak performance age depends on several variables.

Objective: The aim of our study was to identify the peak performance age of athletes in the Czech Republic in terms of middle- and long-distance running and to find out whether it has changed over the years that is between 1945 and 2019 .

Methods: We determined the peak performance age of top fifty, twenty and five runners each year. 22,350 available performances were analysed. Sources of our data were the yearbooks of the Czech Athletic Federation. We have also analysed the differences in peak performance ages across individual disciplines. To determine the statistical significance of the age difference of runners competing on individual tracks, we used the t-test, and through Cohen's d we determined the practical significance of these differences.
\end{abstract}

Results: The peak performance age is significantly higher ( $p=.0015$ and less) for longer tracks as each shorter track demonstrated lower peak performance age. The age of the best runners in Czech 
Republic: $800 \mathrm{~m}: 23.92 \pm 1.77$ years, $1500 \mathrm{~m}: 24.97 \pm 1.65,3000 \mathrm{~m}$ steeple: $26.07 \pm 2.26$ years, $5000 \mathrm{~m}$ : $26.51 \pm 2.30$ years, $10000 \mathrm{~m}$ : $27.91 \pm 4.03$ years, marathon: $30.88 \pm 2.42$ years. We have observed the lowest age of runners during the period starting in the late 1960s to the mid-1980s.

Conclusions: The longer the track is, the higher the age of peak performance. This agrees with the physiological requirements of each disciplines, and it also corresponds with the maturity level of European athletes.

Key words: running, peak performance age, history, middle- and long-distance running, Czech Republic

\section{Introduction}

A lot of studies deal with peak performance age. Some of them set the age of peak performance using a group of medallists who participated in the world's top competitions. There is no universal age of peak performance for running events (or for other sports). The age is always related to a particular event and set of athletes, it also differs for various populations [1-3] and it is also largely an individual matter [2]. The age of peak performance is also influenced by genetic factors, adolescence age, and social and economic impacts. In some communities and cultures, there may be some delay or acceleration in the age of peak performance. A large number of studies indicate a similar age range of peak performance for runners on individual tracks [3-6] but there are also studies that provide different results [1,2].

Middle- and long-distance running represent a group of events that share some common features which, however, make them also different from other athletic events $[7,8]$. In particular, this applies to the structure of performance [7,9]. Nevertheless, there are still some differences between individual events, which are largely based on the somatic and physiological requirements of individual events. The biggest difference is due to a dissimilar proportion of applying aerobic and anaerobic processes which are involved in the creation of the energy needed to achieve the performance. Therefore, for our sample of population we assumed that the age of peak performance would be different for individual events $[1,2]$.

The length and contents of training and also the implementation or absence of individual phases of sports training affect the peak performance age. Athletes who undergo age-appropriate training utilising all stages of sports training are able to maintain their peak performance longer and even maintain it at higher age. By contrast, athletes who use early specialisation in training usually achieve peak performance sooner but are able to maintain it for a shorter period only [4, 9-14]. The aim of our study was to identify the age of peak performance in the Czech Republic in terms of middle- and long-distance running and to find out whether it has changed over the last 75 years. Unlike studies that examined the age of peak performance at global level $[1-3,5,6,15]$ we used a regional study carried out in a country with ten million inhabitants, located in central Europe. The Czech Republic can boast world-class runners such as Emil Zátopek, Josef Odložil, Jakub Holuša, etc. 


\section{Methods}

\section{Participants}

The subject of the study is a time-based research which starts after the end of the Second World War and ends in our present. That means the study uses the entire period of time from which records are available. We analysed the age structure of the top 50 runners every year who were specialising in $800 \mathrm{~m}, 1,500 \mathrm{~m}, 3,000 \mathrm{~m}$ steeplechase $(3,000 \mathrm{~m}$ st.), $5,000 \mathrm{~m}, 10,000 \mathrm{~m}$ and in marathon between 1945 and 2019. Altogether we analysed 22,350 available times/performances achieved by athletes on the above tracks.

\section{Procedures}

The reported age for the given performance was given to the nearest 0.1 year. Sources of our data were the yearbooks of the Czech Athletic Federation (ČAS) and the Czechoslovak Association of Physical Education and Sport (ČSTV) [16-18]. These tables show the top 50 athletes of each season, except for the years 1945-1947, 1990 and 1991, when fewer performances were recorded. An average from the best 50 performances after 1948 was used in the analysis. In each event we observed the peak performance age during each season of a narrow group of top athletes (top 5), wider group (top 20 athletes) and general group (top 50 athletes). We also analysed the differences in the peak performance age across individual events.

\section{Statistical analysis}

By performing the t-test we determined the statistical significance of the differences in the age of runners specialising in individual tracks. Using Cohen's $d$ we determined the practical significance of these differences.

\section{Results}

Figure 1 shows the progress of the performance age of the top 50 runners in the Czech Republic in each event from 1945 (based on the available data) until 2019. It is obvious that the lowest age of peak performance is the lowest for the shortest track and the highest for the longest track. This relationship was also confirmed by statistical calculations, see Table 1. In the group of the top 50 runners there are practically (with a large effect size) and statistically $(p<0.001)$ significant differences in the age in terms of individual events. We may say that there is a direct proportion between the track's length and the peak performance age. 
Figure 1. Age of peak performance in middle and long tracks in the Czech Republic between 1945 and 2019 showing the average age of the top 50 runners for each given year.

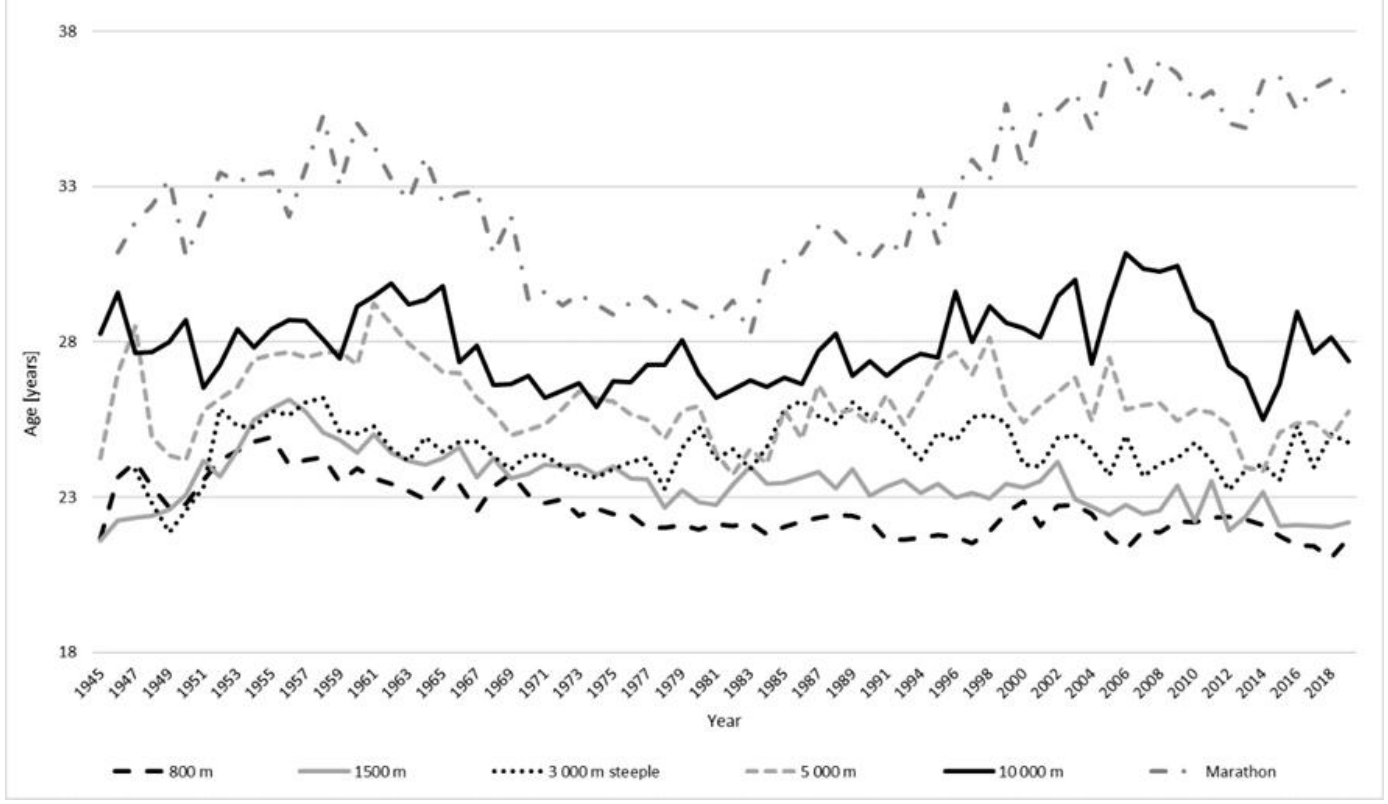

Table 1. Practical significance of the age of peak performance in individual events for 50 best runners each year between 1945 and 2019

\begin{tabular}{lllllll}
\hline & $800 \mathrm{~m}$ & $1,500 \mathrm{~m}$ & $3,000 \mathrm{~m} \mathrm{st}$. & $5,000 \mathrm{~m}$ & $10,000 \mathrm{~m}$ & marathon \\
\hline $800 \mathrm{~m}$ & & 0.90 & 2.26 & 3.27 & 4.96 & 5.27 \\
$1,500 \mathrm{~m}$ & 0.90 & & 1.21 & 2.41 & 4.07 & 4.80 \\
$3,000 \mathrm{~m}$ st. & 2.26 & 1.21 & & 1.43 & 3.13 & 4.26 \\
$5,000 \mathrm{~m}$ & 3.27 & 2.41 & 1.43 & & 1.54 & 3.34 \\
$10,000 \mathrm{~m}$ & 4.96 & 4.07 & 3.13 & 1.54 & & 2.42 \\
marathon & 5.27 & 4.80 & 4.26 & 3.34 & 2.42 & \\
\hline
\end{tabular}

Note: All differences are also statistically significant at $\mathrm{p}<.001$ level.

As for the group of best 20 runners (see Figure 2), which represents the wider group of top runners in each event, we see that the results are almost identical with those for the top 50 runners in the given event. The age is statistically significantly different for individual tracks, and it increases in terms of statistical significance gradually from the shortest to the longest (see Table 2). These differences are also practically significant with a large effect size, except for 1,500 and 3,000 $\mathrm{m}$ steeplechase, where the differences are practically significant with a medium effect size. 
Figure 2. Age of peak performance for middle and long tracks in the Czech Republic showing the average of top 20 runners for each given year during the period between 1945 and 2019.

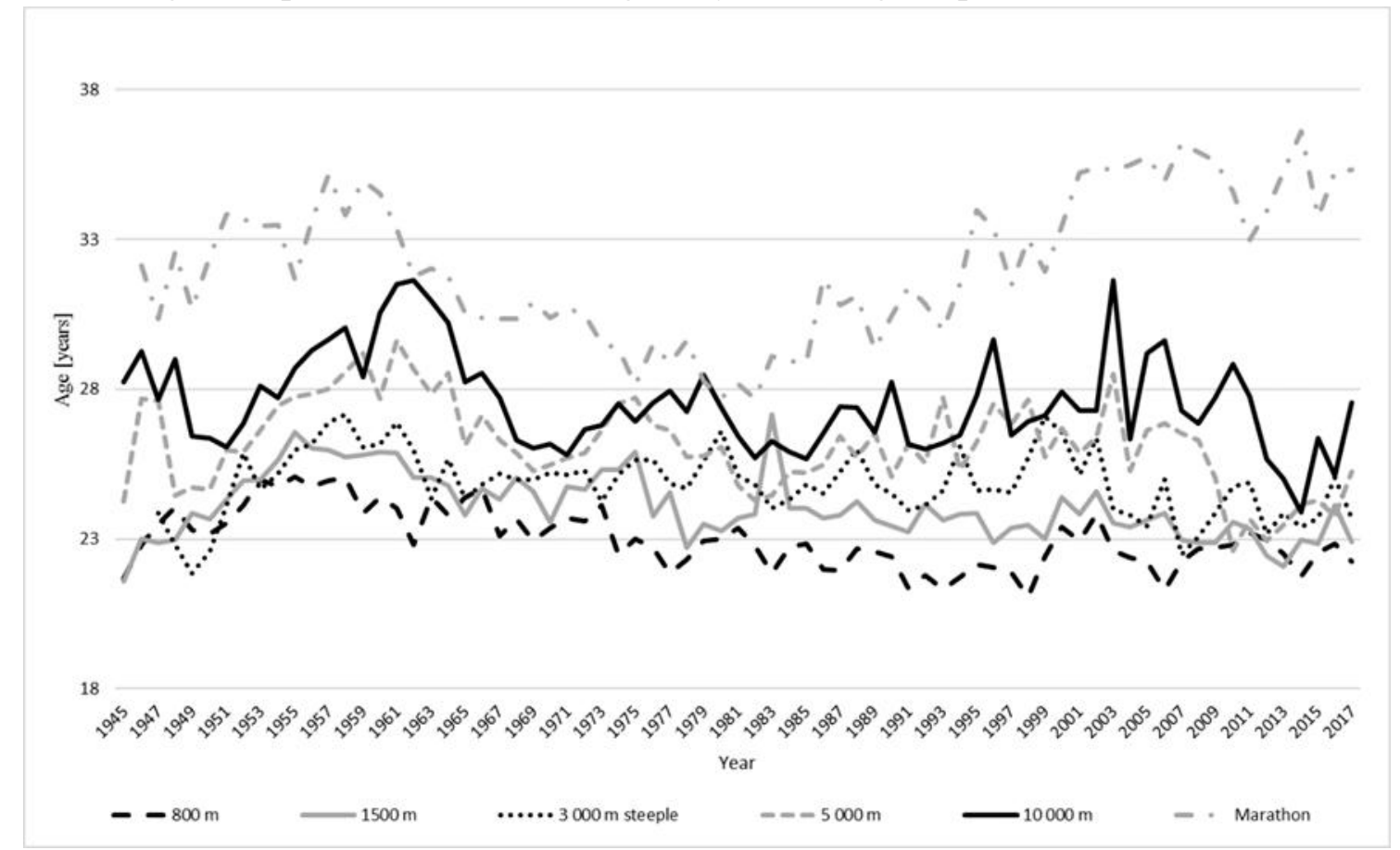

Table 2. Practical significance of the difference in peak performance age between individual events for the top 20 runners each year

\begin{tabular}{lllllll}
\hline & $800 \mathrm{~m}$ & $1,500 \mathrm{~m}$ & $3,000 \mathrm{~m}$ st. & $5,000 \mathrm{~m}$ & $10,000 \mathrm{~m}$ & marathon \\
\hline $800 \mathrm{~m}$ & & 1.02 & 1.76 & 2.50 & 3.47 & 2.74 \\
$1,500 \mathrm{~m}$ & 1.02 & & 0.68 & 1.59 & 2.59 & 2.38 \\
$3,000 \mathrm{~m}$ st. & 1.76 & 0.68 & & 0.99 & 1.98 & 2.13 \\
$5,000 \mathrm{~m}$ & 2.50 & 1.59 & 0.99 & & 0.96 & 1.70 \\
$10,000 \mathrm{~m}$ & 3.47 & 2.59 & 1.98 & 0.96 & & 1.25 \\
marathon & 2.74 & 2.38 & 2.13 & 1.70 & 1.25 & \\
\hline
\end{tabular}

Note: All differences are also statistically significant at $\mathrm{p}<.001$ level.

In the group of top 5 runners in each event (see Figure 3), which represents a narrow group of best runners, they are consistent with the results demonstrated by the group of top 20 runners in the given event. 
Figure 3. Age of peak performance for middle and long tracks in the Czech Republic showing the average of top 5 runners for each given year during the period between 1945 and 2019.

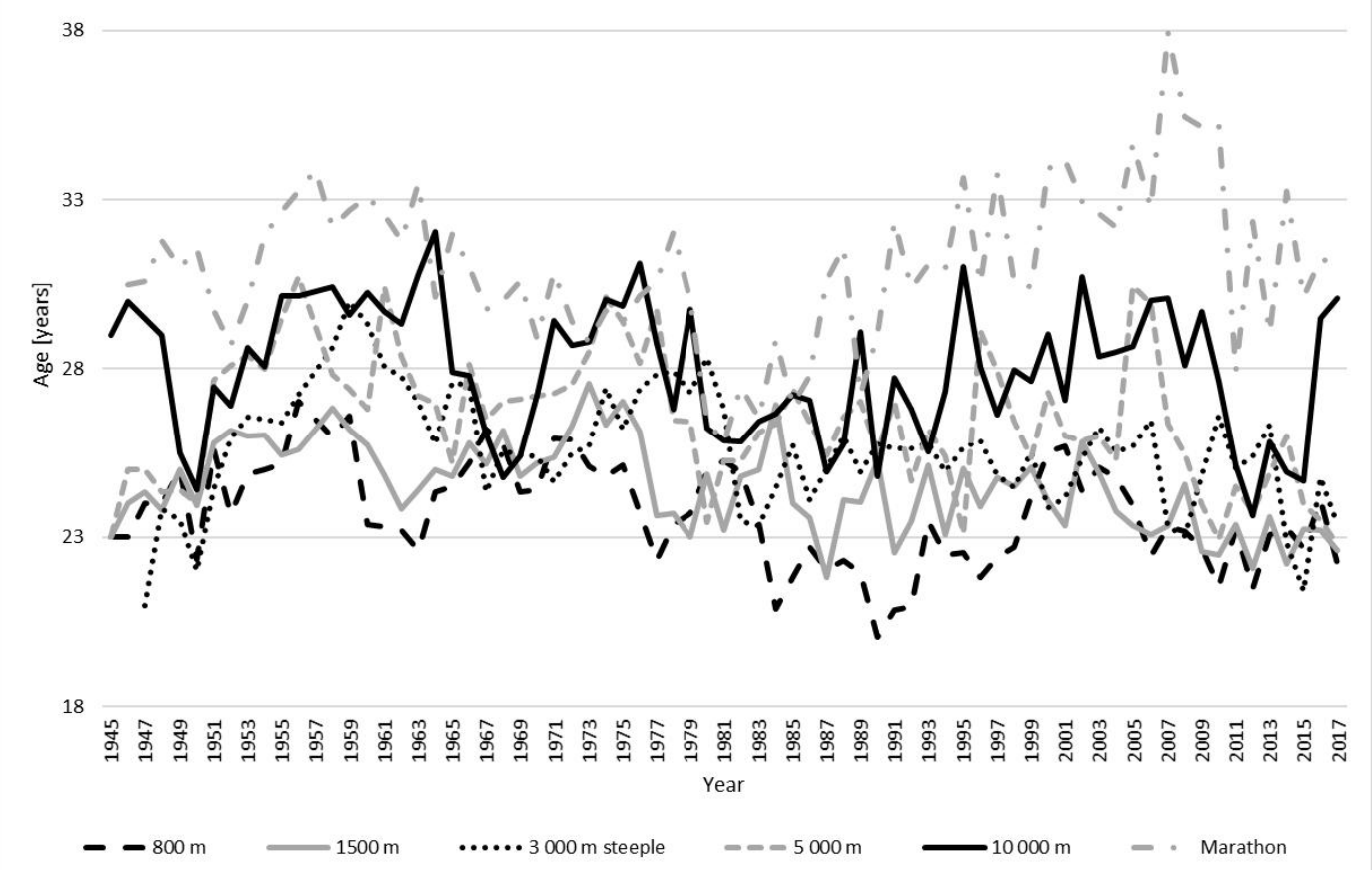

Table 3. Practical significance of the difference in the peak performance age between individual events for the top 5 runners per each year

\begin{tabular}{lllllll}
\hline & $800 \mathrm{~m}$ & $1,500 \mathrm{~m}$ & $3,000 \mathrm{~m} \mathrm{st}$. & $5,000 \mathrm{~m}$ & $10,000 \mathrm{~m}$ & marathon \\
\hline $800 \mathrm{~m}$ & & 0.54 & 1.07 & 1.56 & 2.39 & 2.18 \\
$1,500 \mathrm{~m}$ & 0.54 & & 0.65 & 1.19 & 2.06 & 1.96 \\
$3,000 \mathrm{~m}$ st. & 1.07 & 0.65 & & 0.54 & 1.25 & 1.57 \\
$5,000 \mathrm{~m}$ & 1.56 & 1.19 & 0.54 & & 0.75 & 1.27 \\
$10,000 \mathrm{~m}$ & 2.39 & 2.06 & 1.25 & 0.75 & & 0.84 \\
marathon & 2.18 & 1.96 & 1.57 & 1.27 & 0.84 & \\
\hline
\end{tabular}

Note: All differences are also statistically significant at $\mathrm{p}<.001$ level, excluding: $800 \mathrm{~m} \times$ $1,500 \mathrm{~m}(\mathrm{p}=.0012), 3,000 \mathrm{~m}$ st. $\times 5,000 \mathrm{~m}(\mathrm{p}=.0015)$.

The age is statistically different for individual tracks, and it increases from the shortest to the longest - the significance of the statistic is increasing gradually (see Table 3). These differences are also practically significant with a large effect size, with the exception of the following track pairs: $800 \mathrm{~m}$ and $1,500 \mathrm{~m}, 1,500$ and $3,000 \mathrm{~m}$ steeplechase, $3,000 \mathrm{~m}$ steeplechase and 5,000 m, 5,000 $\mathrm{m}$ and $10,000 \mathrm{~m}, 10,000 \mathrm{~m}$ and marathon, i.e. track pairs that are closest to each other. For these pairs of tracks, the differences are statistically significant with a medium effect size.

The average age of the best runners in each year and in each group (from the top five to the top fifty in each year) is shown in Table 4. These data confirm the increase in the age with the increasing track length. 
Table 4. Age (average \pm SD) of the best runners in different groups between 1945 and 2019 in individual events

\begin{tabular}{lllllll}
\hline & $\begin{array}{l}\text { top 50 in } \\
\text { each year - } \\
\text { age [years] }\end{array}$ & $\begin{array}{l}\text { top 30 in } \\
\text { each year - } \\
\text { age [years] }\end{array}$ & $\begin{array}{l}\text { top 20 in } \\
\text { each year - } \\
\text { age [years] }\end{array}$ & $\begin{array}{l}\text { top 10 in } \\
\text { each year - } \\
\text { age [years] }\end{array}$ & $\begin{array}{l}\text { top 5 in } \\
\text { each year - } \\
\text { age [years] }\end{array}$ & $\begin{array}{l}\text { top 3 in } \\
\text { each year - } \\
\text { age [years] }\end{array}$ \\
\hline $800 \mathrm{~m}$ & $22,60 \pm 0,89$ & $22,79 \pm 0,95$ & $22,96 \pm 1,00$ & $23,25 \pm 1,24$ & $23,73 \pm 1,52$ & $23,92 \pm 1,77$ \\
$1,500 \mathrm{~m}$ & $23,44 \pm 0,96$ & $23,72 \pm 1,05$ & $24,05 \pm 1,09$ & $24,39 \pm 1,34$ & $24,50 \pm 1,30$ & $24,97 \pm 1,65$ \\
$3,000 \mathrm{~m}$ st. & $24,59 \pm 0,87$ & $24,63 \pm 0,89$ & $24,83 \pm 1,11$ & $25,13 \pm 1,51$ & $25,54 \pm 1,78$ & $26,07 \pm 2,26$ \\
$5,000 \mathrm{~m}$ & $26,07 \pm 1,19$ & $26,02 \pm 1,23$ & $26,12 \pm 1,48$ & $26,15 \pm 1,68$ & $26,47 \pm 1,96$ & $26,51 \pm 2,30$ \\
$10,000 \mathrm{~m}$ & $27,93 \pm 1,21$ & $27,69 \pm 1,22$ & $27,59 \pm 1,59$ & $27,70 \pm 1,81$ & $27,94 \pm 1,97$ & $27,91 \pm 4,03$ \\
marathon & $32,77 \pm 2,51$ & $32,12 \pm 4,50$ & $31,73 \pm 4,41$ & $31,17 \pm 4,28$ & $30,71 \pm 4,26$ & $30,88 \pm 2,42$ \\
\hline
\end{tabular}

\section{Discussion}

The situation in Central Europe was very complicated after the end of the Second World War and it was not easy to do sports. However, these conditions were improving rapidly and supported a quick development of sports. In Czechoslovakia, the number of available stadiums was increasing steadily, especially during the 1960s. The first athletics hall was opened in 1968 in Jablonec and two years later the first track with artificial surface was built in Strahov, Prague. Tracks in Ostrava and Třinec quickly followed [19-21]. The construction of three other halls and several other tracks with artificial surface followed and in 1988 seven Tartan surface stadiums were available in the Czech Republic. From the 1950s, sport became not only a part of social life, but also an instrument of propaganda. This was one of the reasons why top-level sport was supported by the state [19-21]. Improved conditions for athletes were mainly provided in so-called army sports clubs and the best state support available in the mid-1970s was provided through top sports centres (SVS) [20, 22]. Changes after 1989 caused the breakdown of the existing system which provided a lot of support for our athletes and, as a result, a major decline in the performance of top athletes belonging to the wider group, followed [23]. They are still not able to establish and provide a full replacement for the previous support system [21,23].

We have recorded the lowest age of runners during the period starting in the late 1960 s to the mid-1980s, both for a group of the top 50 runners in the given year and for the top 20 and top 5 runners in the given year. This period corresponds with the period of peak running performances achieved in the Czech Republic [23] which was also the period during which the state provided the highest support for top-level sport [22]. The average performance in the marathon event shows a different course than the other events in all monitored groups. The reason may be that this event is very different from others. It is the only one of the monitored events where the athletes compete outside of the stadium. A marathon is the only event where unregistered competitors may enrol. Nevertheless, some of these athletes "end up" among the 50 best athletes of the season. These athletes are usually significantly older than the average marathon runner. This has been evident mainly in the last 25 years. Looking at the numbers of participants in individual marathon events we see that it has become quite fashionable to run a marathon $[8,24]$. The increase in the age of marathon runners has been gradually occurring, particularly after 1995, which corresponds with the great running boom in the Czech Republic [21] due to the need to make up for the absence of spontaneous and 
natural exercise $[8,25]$. From that year on, a series of half marathon and marathon races started in the Czech Republic where endurance running has become very popular.

Another difference of this event is that top-level athletes usually compete in the marathon track only twice a year [7]. It is true that the longer the race track, the smaller the number of top-level starts are possible, which is again due to the nature of the event $[8,25]$. That is why external influences (especially the weather) play a major role in marathon running as there may be no opportunity to improve the performance in the next race.

The difference in the age is more significant the greater the difference in track length. This is consistent with other studies that deal with this topic $[3,5,6,26]$ as well as with the characteristics of individual events and the physiological requirements of each event $[7,8]$. Some studies dealing with global sporting competitions show that the age of peak performance in endurance events is different (lower) than those mentioned in our conclusions. This is due to the success of African runners who achieve peak performance earlier in their lives than runners from central Europe $[1,2,15]$. In our sample of the top five runners - in each year, the peak performance age for middle-distance tracks is less than 1 year lower, for endurance runs it is 0.5-1.5 years higher than the peak performance age published Vobr [5] for world medallists, and it is almost identical with the conclusions of the study focusing on the age of medallists who competed at the Olympic Games until 1980 [3] when African runners were not so dominant.

The peak performance age established by our survey confirms that under Central European conditions it is advisable to avoid premature specialisation and focus on ageappropriate training instead. Many talents who reach the age when they should be at their best performance levels are no longer active athletes [10]. This suggests that long-term systematic work leads to peak performance, and it should not end at adolescence age.

We may say that the greatest fluctuations in the peak performance age seen during the monitored period are in marathon running. The age curve of the best runners in the Czech Republic corresponds, to a certain extent, with the level of support athletes receive from the state. During the previous period when many top sports centres existed and where multiply more runners specialising in various events were supported, the peak performance age was significantly lower than it is now. We believe, however, that the results provided by our study can be helpful and useful when planning for preparations, training programmes or for sport strategies.

\section{Conclusion}

In our study we have presented the age level of the best runners specialising in middle and long tracks in the Czech Republic and Czechoslovakia after the end of the Second World War all the way to 2019 during individual years. We have found significant differences in the age of peak performance between individual events and we may conclude that the longer the track is, the higher the age of peak performance. This actually agrees with the period of individual peak motor abilities and physiological requirements of each event, and it also corresponds with the maturity level of European athletes. We have also established the progress of the peak performance age over the monitored period. We may say that the greatest fluctuations in the peak performance age during the monitored period are seen in marathon 
running, where the period with the highest level of performance in history (1970s and 1980s) corresponds to the lowest age of runners and vice versa.

\section{Conflict of interest}

There were no conflicts of interest.

\section{References}

[1] Aschmann A, Knechtle B, Cribari M, Rüst CA, Onywera V, Rosemann T, Lepers R. Performance and age of African and non-African runners in half-and full marathons held in Switzerland, 2000-2010. Open access journal of sports medicine. 2013; 4: 183.

[2] Knechtle B, Aschmann A, Onywera V, Nikolaidis PT, Rosemann T, Rüst CA. Performance and age of African and non-African runners in World Marathon Majors races 2000-2014. Journal of sports sciences. 2017; 35(10): 1012-1024.

[3] Schulz R, Curnow C. Peak performance and age among superathletes: track and field, swimming, baseball, tennis, and golf. Journal of Gerontology. 1988; 43(5): 113-120.

[4] Bompa TO. Total Training for Young Champions. Proven conditioning programs for athletes ages 6 to 18. Humans Kinetics. 2000.

[5] Vobr R. Vývoj věku vrcholné výkonnosti v atletice, plavání, běžeckém lyžování, ledním hokeji a fotbalu v letech 1970-2007. [Development of the age of top performance in athletics, swimming, cross-country skiing, ice hockey and football in the years 1970-2007]. University of South Bohemia in České Budějovice. 2009. Czech.

[6] Vobr R. Identification of peak performance age in track and field athletics. International Journal of Performance Analysis in Sport. 2014; 14(1): 238-251.

[7] Neumann G, Pfützner A, Berbalk A. Successful endurance training. Meyer \& Meyer Verlag. 2000.

[8] Noakes T. Lore of running. Human Kinetics. 2003.

[9] McArdle WD, Katch FI, Katch VL. Essentials of exercise physiology (International ed.). Philadelphia [etc.]: Wolters Kluwer. 2016.

[10] Bahenský P. Success of elite adolescent female runners in adulthood. Studia Sportiva. 2019; 13(1): 6-16.

[11] Bahenský P, Bunc V. Trénink mládeže v bězích na střední a dlouhé tratě. [Training of Young Runners in Medium and Long-Distance Tracks]. Prague. Karolinum. 2018. Czech.

[12] Callender SS. The Early Specialization of Youth in Sports. Athletic Training \& Sports Health Care. 2010; 2(6): 255-257.

[13] Kenney WL, Wilmore J, Costill D. Physiology of Sport and Exercise 6th Edition. Human kinetics. 2015.

[14] Moss D, Dick RW. Avoid Early Specialization for Runners. Tricks of the Trade for Middle Distance, Distance \& Cross-Country Running. 2004; 6(1): 4-9.

[15] Hollings SC, Hopkins WG, Hume PA. Age at peak performance of successful track \& field athletes. International Journal of Sports Science \& Coaching. 2014; 9(4): 651-661.

[16] Janecký A, Kohlmann Č, Nestával J, Sýkora M. Lehkoatletické výkony 1952. [Athletics outcomes 1952]. Prague. Nakladatelství Orbis Praha. 1953. Czech.

[17] Kohlmann Č. Lehkoatletické výkony 1969. [Athletics outcomes 1969]. Prague. Czech Athletic union. 1969. Czech. 
[18] Skočovský M, Klvaňa V, Brandejský P, Alter M, Dvořák S, Hetfleiš J, . . Šroubek V. Tabulky České republiky 2006, mužské složky. [Tables of the Czech Republic 2006, male components]. In: M. Urban, editor. Atletické výkony 2006 [Athletics outcomes 1969]. Prague. Czech Athletic union. 2006. 102-159. Czech.

[19] Jirka J, Popper J, Hrnčíř J, Skočovský M, Vaněk K, Vomáčka V. Malá encyklopedie atletiky. [A small encyclopedia of athletics]. Prague. Olympie. 1990. Czech.

[20] Jirka J, Havlín J, Hrnčíř S, Macák F, Trkal V, Fikejz J, . . Vyčichlo J. et al. Sto let královny. [One hundred years of the queen]. Prague. Iris. 1997. Czech.

[21] Slavík H, Osoba M. 120 let české atletiky. [120 years of Czech athletics]. Prague. Czech Athletic union. 2016. Czech.

[22] Ptáčníková S. Organizační vývoj Správy tělovýchovy a vrcholového sportu FMV a jejích nástupců v letech 1974 - 1993. [Organizational development of the Administration of Physical Education and Top Sport FMV and its successors in the years 1974 - 1993] Internet version of the Proceedings AMV 1/2003. [online]. 2014 [cit. 2014-02-23]. Available from: http://www.abscr.cz/data/pdf/sbornik/sbornik1-2003/vyvoj_stvs.pdf .

[23] Bahenský P, Tlustý P. Analýza vývoje výkonnosti v běhu mužů na 5000 m v ČR 19452016. [Analysis of the development of performance capacity in men's 5,000 meter run in the Czech Republic during 1945-2016]. Studia Kinanthropologica. 2017; 18(2): 97-107.

[24] Nikolaidis PT, Onywera VO, Knechtle B. Running performance, nationality, sex, and age in the $10-\mathrm{km}$, half-marathon, marathon, and the 100-km ultramarathon IAAF 19992015. The Journal of Strength \& Conditioning Research. 2017; 31(8): 2189-2207.

[25] Janssen I, Katzmarzyk PT, Boyce WF, Vereecken C, Mulvihill C, Roberts C, ... Pickett W. Comparison of overweight and obesity prevalence in school-aged youth from 34 countries and their relationships with physical activity and dietary patterns. Obesity Reviews. 2005; 6(2): 123-132.

[26] Allen SV, Hopkins WG. Age of peak competitive performance of elite athletes: a systematic review. Sports Medicine. 2015; 45(10): 1431-1441.

\section{List of tables:}

Table 1. Practical significance of the age of peak performance in individual events for 50 best runners each year between 1945 and 2019

Table 2. Practical significance of the difference in peak performance age between individual events for the top 20 runners each year

Table 3. Practical significance of the difference in the peak performance age between individual events for the top 5 runners per each year

Table 4. Age (average \pm SD) of the best runners in different groups between 1945 and 2019 in individual events

List of figures:

Figure 1. Age of peak performance in middle and long tracks in the Czech Republic between 1945 and 2019 showing the average age of the top 50 runners for each given year

Figure 2. Age of peak performance for middle and long tracks in the Czech Republic showing the average of top 20 runners for each given year during the period between 1945 and 2019 Figure 3. Age of peak performance for middle and long tracks in the Czech Republic showing the average of top 5 runners for each given year during the period between 1945 and 2019 